\title{
Conicity index as an indicator of body fat percentage in adolescents
}

\author{
Mulyasari, I. and Purbowati \\ Nutrition Program Study, Health Science Faculty, Ngudi Waluyo University, Ungaran Timur-Semarang \\ Regency, Central Java 50512, Indonesia
}

\begin{abstract}
Article history:
Received: 29 December 2019

Received in revised form: 4

February 2020

Accepted: 7 February 2020

Available Online: 30 May

2020
\end{abstract}

Keywords:

Adolescents,

Body mass index,

Conicity index,

Body fat percentage

DOI:

https://doi.org/10.26656/fr.2017.4(S3).S04

\begin{abstract}
New indicators have been proposed in order to detect obesity and body fat distribution, such as conicity index (CI). The previous study found that $\mathrm{CI}$ has a significant correlation with high body fat in adolescents. This study aimed to assess the association of Conicity Index (CI) with Body Mass Index (BMI) and Body Fat Percentage (\%BF) and evaluated the accuracy of $\mathrm{CI}$ based on $\% \mathrm{BF}$ as gold standard for identification of obesity in adolescents. This cross-sectional study consisted of 620 adolescents (283 boys and 337 girls) aged 14-18 years. The correlation was tested using Spearman analysis. Obesity was based on age-and-sex specific body fat percentage cut-off values of body fat reference curves for children from Growth Foundation. Receiver operating characteristic (ROC) curve analyses were used to assess the accuracy of CI as a diagnostic test of obesity in adolescents. This study showed that CI was significantly correlated with BMI (boys: $\mathrm{r}=$ $0.485, \mathrm{p}<0.0001$; girls: $\mathrm{r}=0.302, \mathrm{p}<0.0001$ ) and $\% \mathrm{BF}$ (boys: $\mathrm{r}=0.544, \mathrm{p}<0.0001$; girls: $r$ $=0.347, \mathrm{p}<0.0001$ ). The area under curve (AUC) of CI for the diagnostic of obesity were over 0.9 for boys and over 0.7 for girls. The cut-off values for defining obesity were 1.13 (Sensitivity (Se) and Specificity $(\mathrm{Sp})>0.8$ ) for boys and 1.14 (Se and $\mathrm{Sp}>0.6$ ) for girls. In conclusion, CI positively associated with BMI and \% BF. CI is more accurate in boys than girls for the screening of excess adiposity in adolescents.
\end{abstract}

\section{Introduction}

Obesity in adolescents is a new emerging nutrition problem in Indonesia. Its prevalence has escalated based on Basic Health Survey in Indonesia. Obesity in adolescents aged $13-15$ years has increased from $2.5 \%$ in 2013 to $6.7 \%$ in 2018 . In adolescents aged $16-18$, the trend has increased from $1.9 \%$ in 2013 to $4.0 \%$ in 2018 (National Institute of Health Research and Development,2013; National Institute of Health Research and Development,2018). Thus, screening program is needed in adolescents' group, since obesity in adolescents can trigger patterns obesity in adulthood and increase risk of non-communicable diseases (NCD) like diabetes mellitus and cardiovascular diseases at a younger age (World Health Organization, 2014).

Several anthropometry methods have been tested to identify obesity in adolescents. Body mass index (BMI) is widely used as an obesity indicator. In adolescents, BMI is classified based on sex and age (World Health Organization, 2013). BMI indicates fat in general. This index cannot distinguish fat from muscle mass and cannot represent fat distribution. A study found that the correlation between BMI and fat content weaker than that (\%BF) and fat content (Thu Trang et al., 2019). This general obesity index may not be appropriate in predicting NCD.

In epidemiological studies, body fat percentage has been recommended as an obesity indicator and a better predictor for NCD. Higher body fat percentage has correlated with a higher risk of metabolic syndrome (AlBachir and Bakir, 2017). The cardiovascular diseases risk factor also increases in adolescents with body fat percentage higher $20 \%$ in male and $30 \%$ in female (Going et al., 2011).

New indicators have been proposed in order to detect obesity and body fat distribution, such as conicity index (CI). CI is determined based on the measurement of body mass, height, and waist circumference indicator of abdominal obesity. It evaluates waist circumference in relation to weight and height. It assumes that body shape changes with accumulation of fat in the abdomen (Valdez, 1991). The previous study found that CI has a 
significant correlation with high body fat in adolescents (Pelegrini et al., 2015). Asian populations are predisposed to visceral or abdominal adiposity without developing generalized obesity (Steering Committee, 2000). There was limited information about CI for Asian. As far as we know there was no information about CI for Indonesian. Hence, the aim of the study was to assess the association of Conicity Index (CI) with Body Mass Index $(\mathrm{BMI})$ and Body fat percentage (\%BF) and evaluate the accuracy of $\mathrm{CI}$ for identification of obesity in adolescents, especially for Indonesian.

\section{Materials and methods}

\subsection{Design, location, and time}

This diagnostic study was conducted in SMAN 2 Ungaran Central Java Indonesia in November 2017. The school is included in the criteria of the obesogenic environment. The location is in an area close to various fast food restaurants. The school canteen provides high energy snacks such as sweet cakes and various fried foods. While on the other hand, most students use motorbikes to go to school. The study tested $\mathrm{CI}$ as obesity indicator based on \%BF parameter as a gold standard and assess its correlation to $\mathrm{BMI}$ and $\% \mathrm{BF}$.

\subsection{Sampling}

The sampling technique was total sampling technique. The total number of subjects in this study were 620 students ( 283 boys, 337 girls). The inclusion criteria were not suffering from fever and not in the period of menstruation at the time of the measurement. It will influence body fat percentage measurement result. The study was ethically approved by the Ethics Commission of Health Research, Public Health Faculty of Dipo-negoro University (No. 281/EC/FKM/2017).

\subsection{Data collection}

Each student was recorded their date of birth and sex data. Every subject was wearing a sports uniform and barefoot on anthropometry measurement. Height (Ht) was measured by microtoise (accuracy $=0.1 \mathrm{~cm}$ ), Omron body composition model HBF-358-BW was used for measuring body weight (Wt) and $\% \mathrm{BF}$ and measuring tape for measuring waist circumference (WC) to the nearest $0.1 \mathrm{~cm}$. All anthropometry data was taken with anthropometry standard measurements (Gibson, 2005). For maintaining the privacy and comfort of the subject, the measurement of WC was performed in a closed room with the same sex enumerator. Measurements were done by nutrition lecturer and students.

\subsection{Data analysis}

Data were expressed in mean and standard deviation.
Anthropometric parameters were taken as a continuous variable. Correlation between variables was tested using Spearman analysis. The significant level was set at $\mathrm{p}<0.05$. The sensitivity (Se) and specificity (Sp) of CI as an indicator of obesity were determined with cut-off value based on $\% \mathrm{BF}$ as the gold standard. $\% \mathrm{BF}$ was classified using percentile scores for sex and age $\left(\leq 2^{\text {nd }}\right.$ percentile $=$ under fat, $>2^{\text {nd }}-<85^{\text {th }}$ percentile $=$ normal, $\geq 85^{\text {th }}-<95^{\text {th }}$ percentile $=$ overfat, $\geq 95^{\text {th }}=$ obese) (McCarthy et al., 2006). CI was calculated from the formula (Pitanga and Lessa, 2005):

Receiver operating characteristics (ROC) curves and area under the curve (AUC) for ROC's were obtained by

$$
C I=\frac{W C(\mathrm{~m})}{0.109 \times \sqrt{\frac{W t(\mathrm{~kg})}{H t(m)}}}
$$

plotting sensitivity against the false-positive rate (1specificity). The Youden index (J) was used to determine the optimal cut-off value for CI for identification obesity $(\mathrm{J}=$ sensitivity + specificity-1).

\section{Results}

The total number of the students met the inclusion criteria was 620 students from 732 students. 112 students from 732 students did not meet the inclusion criteria, data didn't complete, and absent while data were taken. The distribution of subjects based on sex were 283 (45.65\%) boys and 337 (54.35\%) girls. The mean of \% $\mathrm{BF}$ and CI were lower in boys than girls, while the mean of BMI was lower in girls. There was a difference of $\%$ $\mathrm{BF}$ and CI between the sexes. CI positively associated with BMI and \%BF for both sexes. Subject characteristics are shown in Table 1. Correlation between CI with BMI and \%BF are shown in Table 2.

Table 1. Subject characteristics

\begin{tabular}{lcccc}
\hline Variables & Min-Max & $\begin{array}{c}\text { Boys } \\
(\mathrm{n}=283)\end{array}$ & $\begin{array}{c}\text { Girls } \\
(\mathrm{n}=337)\end{array}$ & $\mathrm{p}$ \\
\hline Age $(\mathrm{y})$ & $14.1-18.4$ & $16.16 \pm 0.7$ & $16.01 \pm 0.6$ & \\
BMI $\left(\mathrm{Kg} / \mathrm{m}^{2}\right)$ & $13.89-39.53$ & $21.44 \pm 4.8$ & $20.96 \pm 3.7$ & 0.993 \\
\%BF $(\%)$ & $5.0-38.1$ & $14.28 \pm 6.5$ & $24.57 \pm 4.1$ & $<0.0001$ \\
CI & $0.93-1.50$ & $1.09 \pm 0.05$ & $1.12 \pm 0.06$ & $<0.0001$ \\
\hline
\end{tabular}

$\mathrm{n}=$ total subject, $\mathrm{BMI}=$ body mass index, $\% \mathrm{BF}=$ body fat percentage, $\mathrm{CI}=$ conicity index

Table 2. Correlation between $\mathrm{CI}$ with $\mathrm{BMI}$ and $\% \mathrm{BF}$

\begin{tabular}{cccccc}
\hline & \multicolumn{2}{c}{ BMI } & \multicolumn{2}{c}{$\% \mathrm{BF}$} \\
\cline { 2 - 6 } & & $\mathrm{r}$ & $\mathrm{p}$ & $\mathrm{r}$ & $\mathrm{p}$ \\
\hline $\mathrm{CI}$ & Boys & 0.485 & $<0.0001$ & 0.544 & $<0.0001$ \\
& Girls & 0.302 & $<0.0001$ & 0.347 & $<0.0001$ \\
\hline BMI $=$ body & mass & index, & $\% \mathrm{BF}=$ body & fat & percentage, \\
\multicolumn{2}{l}{ CI=conicity index }
\end{tabular}




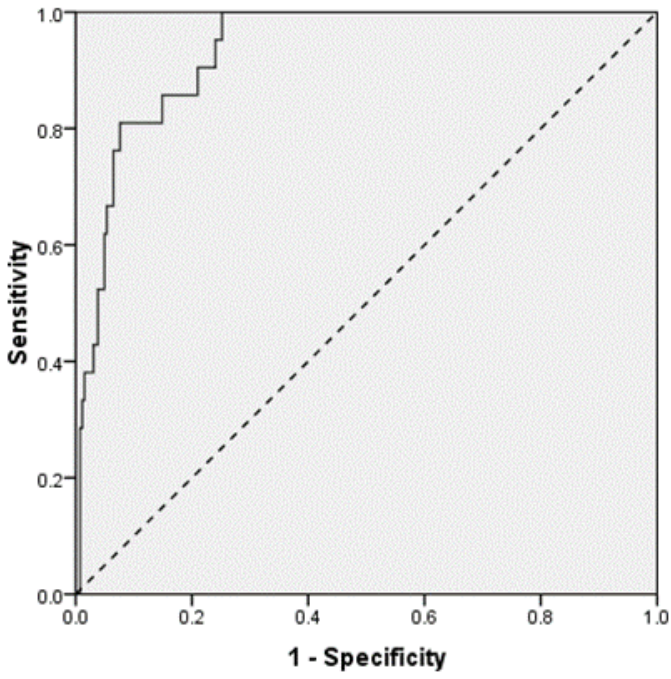

Figure 1. Receiver-operating characteristic (ROC) curves for obese in boys (left) and girls (right)

CI accuracy for evaluating obese was measured using AUC (Area Under Curve). The results are shown in Table 3 and Figure 1. CI has excellent accuracy (AUC $>0.9)$ in boys and good accuracy in girls to determine obese. The optimal cut-off point for determining obese is higher in girls than boys (boys $=1.13$, girls $=1.14$ ). Sensitivity and specificity are better in boys than girls (boys: $\mathrm{Se}$ and $\mathrm{Sp}>0.8$; girls: $\mathrm{Se}$ and $\mathrm{Sp}>0.6$ ) (Table 4).

Table 3. Area under curve (AUC) for CI to determine obese based on $\% \mathrm{BF}$

\begin{tabular}{ccccccc}
\hline & & AUC & SE & p & Lower & Upper \\
\hline \multirow{2}{*}{ CI } & Boys & 0.93 & 0.019 & $<0.0001$ & 0.896 & 0.972 \\
& Girls & 0.76 & 0.031 & 0.031 & 0.569 & 0.944 \\
\hline
\end{tabular}

$\% \mathrm{BF}=$ body fat percentage, $\mathrm{CI}=$ conicity index

Table 4. Optimal cut-off point for CI to determine obese

\begin{tabular}{ccccc}
\hline & & Cut-off & $\mathrm{Se}$ & $\mathrm{Sp}$ \\
\hline \multirow{2}{*}{$\mathrm{CI}$} & Boys & 1.13 & 0.857 & 0.851 \\
& Girls & 1.14 & 0.667 & 0.668 \\
\hline
\end{tabular}

$\mathrm{CI}=$ conicity index

\section{Discussion}

Conicity index is a proposed index as a model to assess obesity and body fat distribution. It was proposed by Valdez in 1991 (Valdez, 1991). This study aimed to evaluate this index to assess obesity in Indonesian adolescents. This model evaluates abdomen adiposity determination by waist circumference with weight and height.

Our study showed that the conicity index positively associated with BMI and body fat percentage. The correlation was stronger in boys than in girls. Hence, adolescents with higher conicity index indicate higher BMI and body fat percentage. Conicity index may be

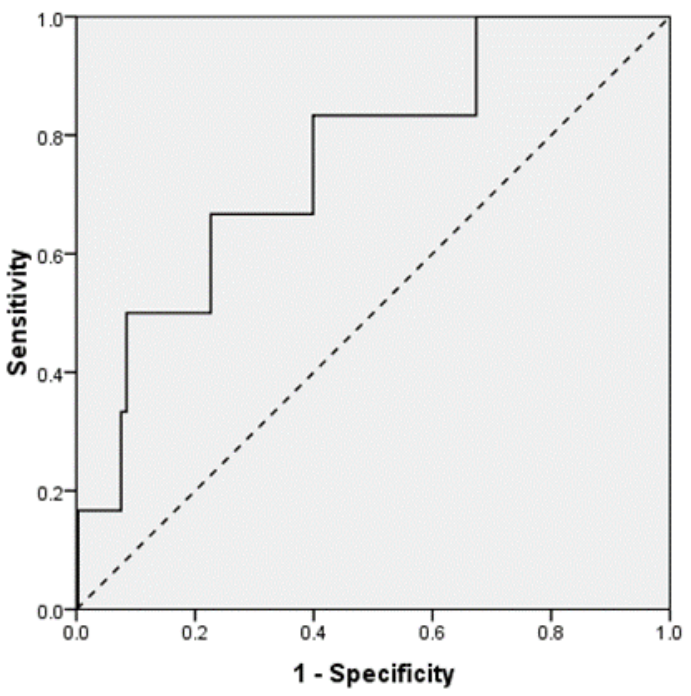

correlated with obesity both in general and in high body fat. Other study found that conicity index associated with trunk fat (Taylor et al., 2000). A similar result also found in male adults in West Bengal India. Conicity index had positive correlation with BMI $(\mathrm{r}=0.32, \mathrm{p}<0.001)$ and body fat percentage $(r=0.41, p<0.001)$ (Chakraborty and Bose, 2009). Study in female adolescents aged 10-19 years in Brazil showed that subjects with excess weight had a higher value of conicity index. It also demonstrated that conicity index can predict high body fat (Pires et al., 2017).

Conicity index had a weak correlation with body fat percentage in both sexes. The previous study in children and adolescents aged 3-19 years found similar results (Taylor et al., 2000). In both sexes after adjusting age, conicity index had weak correlation with trunk fat $(\mathrm{r}=$ 0.46 in boys; $r=0.31$ in girls). The correlation was weaker than waist circumference with trunk fat $(\mathrm{r}=0.84$ in boys; $r=0.83$ in girls) (Taylor et al., 2000). Other study showed that conicity index in young female aged 19-23.5 years had positive correlation with body fat both in $\mathrm{kg}$ and percent $(\mathrm{r}=0.31-0.46)$ (Socha, 1999).

The values of the area under the ROC curve of conicity index in the prediction of body fat in adolescent indicated that conicity index was able for identifying obesity from body fat percentage. The percentage under the curve was higher in boys than girls. The sensitivity and specificity are also better in boys than girls. This present study demonstrated the better ability of conicity index in identifying body fat percentage. In the previous study in Brazilian school children aged 15-17 years, conicity index had lower percentage under the curve when compared to this study (Pelegrini et al., 2015). Other report stated conicity index also able to identify trunk fat mass with a percentage more than $80 \%$ in both sexes (Taylor et al., 2000). 
There is no consensus of high body fat based on conicity index. Our study showed an optimal cut off point 1.13 for boys and 1.14 for girls. Other studies proposed 1.12-1.16 for boys and 1.06-1.12 for girls (Taylor et al., 2000; Pelegrini et al., 2015).

The present study has some limitations. Conicity index is proposed anthropometry indicator to evaluate obesity. Only a few studies discussed conicity index and high body fat which made this study has limitations of comparing the results. This study did not consider body fat distribution and growth velocity differences in adolescent related to their growth period. Due to the differences, it might be biased in diagnosing obesity.

\section{Conclusion}

In conclusion, this study showed that the conicity index was able to identify obesity from body fat percentage in adolescents. Based on this study results, conicity index may become one of anthropometry indicators to identify obesity. The difficulty of conicity index is only due to the complexity of calculating using its formula. This study results can be used as preliminary information that conicity index has had good sensitivity for determining obesity, especially in Indonesian adolescents. Further research about conicity index as an indicator of obesity in adolescent is needed to include subject with a wider range of age and ethnic variations. The cut-off point for diagnosing obesity should be developed for each age and sex.

\section{Conflict of Interest}

The authors declare no conflict of interest.

\section{Acknowledgement}

We wish to express our sincere thanks to Ngudi Waluyo University for the research grant for this study.

\section{References}

Al-Bachir, M. and Bakir, M.A. (2017). Relationship between body fat percentage determined by bioelectrical impedance analysis and metabolic risk factors in Syrian male adolescents (18-19 years). Anthropological Review, 80(1), 103-113. https:// doi.org/10.1515/anre-2017-0006

National Institute of Health Research and Development. (2018). Indonesia Basic Health Survey 2018. Jakarta, Indonesia: National Institute of Health Research and Development

National Institute of Health Research and Development. (2013). Indonesia Basic Health Survey 2013. Jakarta. Retrieved on October 8, 2018 from National Institute of Health Research and Development website: http:// www.depkes.go.id/resources/download/general/Hasil Riskesdas 2013.pdf?opwvc $=1$

Chakraborty, R. and Bose, K. (2009). Central Adiposity, Body Mass Index and Body fat percentage among Bengalee Hindu Male Slum Dwellers of Dum Dum, West Bengal, India. The Open Obesity Journal, 1(1), 32-37.

https:// doi.org/10.2174/1876823700901000032

Gibson, R.S. (2005). Principles of Nutritional Assessment. 2nd ed. New York: Oxford University Press.

Going, S.B., Lohman, T.G., Cussler, E.C., Williams, D.P., Morrison, J.A. and Horn, P.S. (2011). Body fat percentage and Chronic Disease Risk Factors in U.S. Children and Youth. American Journal of Preventive Medicine, 41(4), S77-S86. https://doi.org/10.1016/ j.amepre.2011.07.006

Pitanga, F.J.G. and Lessa, I. (2005). Anthropometric Indexes of Obesity as an Instrument of Screening for High Coronary Risk in Adults in the City of Salvador-Bahia, Arquivos Brasileiros de Cardiologia, 85. https://doi.org/10.1590/S0066782X2005001400006

McCarthy, H.D., Cole, T.J., Fry, T., Jebb, S.A. and Prentice, A.M. (2006). Body Fat Reference Curves for Children. International Journal of Obesity, 30, 598-602. https://doi.org/10.1038/sj.ijo.0803232

Pelegrini, A., Silva, D.A.S., de Lima Silva, J.M.F., Grigolo, L. and Petroski, E.L. (2015). Anthropometric indicators of obesity in the prediction of high body fat in adolescents. Revista Paulista de Pediatria (English Edition), 33(1), 5662. https://doi.org/10.1016/S2359-3482(15)30031-2

Pires, N., Sousa, J., Silva E. Silva, A.C., Sousa Junior, C.M., De Oliveira Barreiros, M. and Cristina, S. (2017). Anthropometric Measures in the Prediction of High Fat Percentage in Female Adolescents. International Journal of Research Studies in Biosciences (IJRSB), 5(1), 16-20. https:// doi.org/10.20431/2349-0365.0501003

Socha, M. (1999). Correlations between selected fatness indices and total body fat estimated by means of the impedance method Małgorzata Socha. Anthropological Review, 62, 25-34. Available at: http://www.ptantropologiczne.pl/en/ckfinder/ userfiles/images/AR/vol062/03socha.pdf (Accessed: 29 August 2019).

Steering Committee (2000). The Asia-Pacific Perspective: Redefining Obesity and Its Treatment. Australia. Retrieved on August 26, 2019 from World Health Organization website: http:// 
www.wpro.who.int/nutrition/documents/docs/

Redefiningobesity.pdf

Taylor, R.W., Jones, J.E., Williams, S.M. and Goulding,

A. (2000). Evaluation of waist circumference, waistto-hip ratio, and the conicity index as screening tools for high trunk fat mass, as measured by dual-energy X-ray absorptiometry, in children aged 3-19 y. American Journal of Clinical Nutrition, 72(2), 490495.

Thu Trang, L., Nam Trung, N., Chu, D.T and Thi Hong Hanh, N. (2019). Article history: Percentage Body Fat is As a Good Indicator for Determining Adolescents Who Are Overweight or Obese: A Cross-Sectional Study in Vietnam Osong Public Health and Research Perspectives. Public Health Research Perspective, 10(2), 108-114. https:// doi.org/10.24171/j.phrp.2019.10.2.10

Valdez, R. (1991). A simple model-based index of abdominal adiposity. Journal of Clinical Epidemiology, 44(9), 955-956. https:// doi.org/10.1016/0895-4356(91)90059-I

World Health Organization (WHO). (2014). Why does childhood overweight and obesity matter?. Retrieved on August 26, 2019 from World Health Organization website: https://www.who.int/dietphysicalactivity/ childhood consequences/en/

World Health Organization (WHO). (2013). WHO Growth reference data for 5-19 years. Retrieved on March 4, 2019 from World Health Organization website: Available at: https://www.who.int/ growthref/en/ 